\title{
COMPARATIVE PERFORMANCE ANALYSIS OF A HYPER-TEMPORAL NDVI ANALYSIS APPROACH AND A LANDSCAPE-ECOLOGICAL MAPPING APPROACH
}

\author{
Amjad Ali $^{\text {a b }}$, C.A.J.M. de Bie ${ }^{a}$, R.G. Scarrott ${ }^{\mathrm{c}}$, Nguyen Thi Thu Ha ${ }^{\mathrm{a}}$, A.K. Skidmore ${ }^{\mathrm{a}}$ \\ a. Faculty of Geo-Information Science and Earth Observation (ITC); University of Twente, 7500 AE, Enschede, \\ The Netherlands-amjad@itc.nl \\ b. Pakistan Space and Upper Atmosphere Research Commission (SUPARCO), SUPARCO Road, Karachi \\ 75270, Pakistan. \\ c. Coastal and Marine Research Centre, Environmental Research Institute, University College Cork, County \\ Cork, Ireland.
}

\section{Commissions VII, WG VII/4}

KEY WORDS: Mapping, Agriculture, Multitemporal, land Use, Land Cover, Crop

\begin{abstract}
:
Both agricultural area expansion and intensification are necessary to cope with the growing demand for food, and the growing threat of food insecurity which is rapidly engulfing poor and under-privileged sections of the global population. Therefore, it is of paramount importance to have the ability to accurately estimate crop area and spatial distribution. Remote sensing has become a valuable tool for estimating and mapping cropland areas, useful in food security monitoring. This work contributes to addressing this broad issue, focusing on the comparative performance analysis of two mapping approaches (i) a hyper-temporal Normalized Difference Vegetation Index (NDVI) analysis approach and (ii) a Landscape-ecological approach. The hyper-temporal NDVI analysis approach utilized SPOT 10-day NDVI imagery from April 1998-December 2008, whilst the Landscape-ecological approach used multitemporal Landsat-7 ETM+ imagery acquired intermittently between 1992 and 2002.

Pixels in the time-series NDVI dataset were clustered using an ISODATA clustering algorithm adapted to determine the optimal number of pixel clusters to successfully generalize hyper-temporal datasets. Clusters were then characterized with crop cycle information, and flooding information to produce an NDVI unit map of rice classes with flood regime and NDVI profile information. A Landscape-ecological map was generated using a combination of digitized homogenous map units in the Landsat-7 ETM+ imagery, a Land use map 2005 of the Mekong delta, and supplementary datasets on the regions terrain, geo-morphology and flooding depths. The output maps were validated using reported crop statistics, and regression analyses were used to ascertain the relationship between land use area estimated from maps, and those reported in district crop statistics.

The regression analysis showed that the hyper-temporal NDVI analysis approach explained $74 \%$ and $76 \%$ of the variability in reported crop statistics in two rice crop and three rice crop land use systems respectively. In contrast, $64 \%$ and $63 \%$ of the variability was explained respectively by the Landscape-ecological map. Overall, the results indicate the hyper-temporal NDVI analysis approach is more accurate and more useful in exploring when, why and how agricultural land use manifests itself in space and time. Furthermore, the NDVI analysis approach was found to be easier to implement, was more cost effective, and involved less subjective user intervention than the landscape-ecological approach.
\end{abstract}

\section{INTRODUCTION}

Agricultural land use mapping is required for the monitoring and planning of agricultural resources at local, regional and continental levels. The increasing global population has growing food requirements, currently met by a combination of both agricultural area expansion and intensification. This requires accurate estimations of crop areas and its spatial distributions (Khan et al., 2010). The availability of current and accurate land use information is vital for food security planning. Supporting this need for information, remote sensing data and its analysis has become a valuable tool for estimating and mapping cropland area, which can aid in such food security monitoring. This study contributes to this issue by focusing on a comparative performance analysis of two mapping approaches: (i) a hy- per-temporal Normalized Difference Vegetation Index (NDVI) analysis approach and (ii) a Landscape-ecological approach.

Hyper-temporal NDVI image datasets are regarded as being those within which images have been acquired at a high frequency for long time (McCloy, 2006; de Bie et al., 2008). They have proven useful in studying the dynamic aspects of crop phenology, and cropping systems due to their easy availability and temporal coverage. The availability of extended NOAA AVHRR, MODIS and SPOT Vegetation and MERIS data has provided the opportunity to study dynamic aspects of land use in detail, with the help of the long-term NDVI data.

Landscape information is considered important for defining spatial planning tasks, and the ultimate management of land use. It does so primarily by contributing to a better understanding of the structure and functions of the area (Turner, 1989). 
Recent advances in remote sensing and geographical information systems technology have not only made a wide variety of data available, but have also made it possible for landscape data at a range of different scales to be handled, compared, and integrated. Therefore mapping using a Landscape-ecological approach is potentially very useful and it is helpful in investigating land and land use aspects (such as flooding, soil hazards, nutrients and water availability). It is worth noting that this approach is based on the integration of land use and landcover interpretations derived from remote sensing inputs from a single timeframe, or from intermittent multiple dates with landscape parameters such as terrain, geomorphology etc.

A number of studies have used either the hyper-temporal NDVI analysis approach e.g. (de Bie et al., 2008; Khan et al., 2010) or Landscape-ecological approach (Zonneveld, 1995; Homer et al., 1997) However, currently there is a lack of information pertaining how the two approaches compare to each other in terms of their performance, accuracy, and applicability. Such information is potentially useful for those seeking to efficiently tailor their approaches to gain the maximum amount of information from studies of similar landscapes. This study explores this comparability, firstly appraising the individual outputs, then comparing the two in terms of their individual performance and proposing the most accurate approach for agricultural land use mapping. In doing so, the study also explored the applicability of both methods, providing an appraisal of their contrasting abilities to capture the spatio-temporal features of land cover and land use that characterised the study area.

\section{MATERIALS AND METHODS}

\subsection{Study area}

The Mekong delta forms the southern region of Vietnam (Figure 1). Agriculture is the predominant economic activity in the region, with an estimated $75 \%$ of the population earning their livelihood from agricultural activities. The primary crop is rice (Oryza spp.), with a complex agricultural land use system involving the cultivation which varies spatially between (i) two annual rice crops, (ii) two rice crops with one upland crop and (iii) three rice crops in the region.

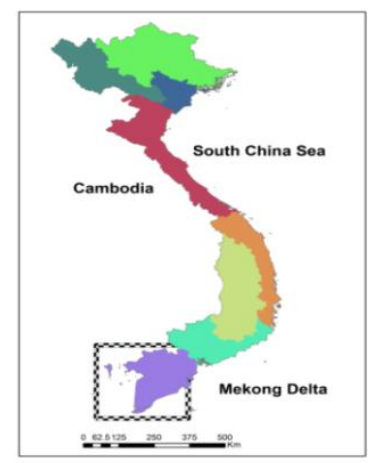

Figure 1. Vietnam map showing the location of the study area (Mekong Delta, Vietnam)

\subsection{Data used}

The hyper-temporal NDVI image dataset was composed of sequential Spot 4 and Spot 5 vegetation NDVI 10-day composite
$1 \mathrm{~km}$ image dataset (384 images), spanning from April 1998 to December 2008. For the Landscape-ecological approach, 10 ETM+ "Enhanced Thematic Mapper" instrument on-board the LANDSAT-7 satellite, having 30 meter spatial resolution (acquired on $1^{\text {st }}$ December $1992,6^{\text {th }}$ November $2000,11^{\text {th }}$ December 2001, $6^{\text {th }}$ January $2001,4^{\text {th }}$ March $2001,16^{\text {th }}$ January 2002 , $4^{\text {th }}$ March 2002, $5^{\text {th }}$ March 2002, $7^{\text {th }}$ March 2002, and $17^{\text {th }}$ March 2002) were used. The Landscape-ecological approach also incorporated a geo-morphological map (Haruyama and Shida, 2008), a flooding depth map (Minh, 1995; Yamashita, 2005) and the regional land use map 2005 (College of Agriculture Can Tho University, 2005). Land use Statistics collected from the General Statistics office of Vietnam, were used for validation purposes.

Field data were also collected from the $20^{\text {th }}$ September to $20^{\text {th }}$ October 2008, and pertained to information on field crop calendars and land observations. The survey involved 118 digitizing rice paddy fields, and crop calendar data collected from farmers through interviews. Sampling stratification and field selection was dictated by the generated NDVI cluster map. Fields located within NDVI clusters which coincided spatially with designated "rice" areas from the land use map 2005 were investigated. Selection was also dictated on the basis of whether or not the field's farmer was available for interview during the survey period.

\subsection{The hyper-temporal NDVI analysis approach}

The hyper-temporal NDVI image dataset (composed of sequential 10-day composited NDVI SPOT images from April 1998 to December 2008) were clustered using an Iterative SelfOrganizing Data Analysis Technique (ISODATA). The image dataset stack was classified in 91 ISODATA runs, producing 91 cluster images outlining the distributions of 10 to 100 clusters, and the associated signature files for each cluster. Subsequent calculation and analysis of average and minimum cluster divergence statistics (Swain and Davis, 1978) determined the choice of the optimal number of clusters to generalise the data.

The method sought an output cluster number with coincident locally high average and minimum separability values. The selected cluster map and its cluster profiles were then explored for temporal and spatial patterns using field data. Each clusters flooding regime was ascertained by associating low NDVI values in mean stacked NDVI images with flooding. Finally an NDVI unit classification map was produced by compiling detailed legend incorporating information on the flooding regime, and cropping regime for each class.

\subsection{The Landscape-ecological approach}

The Landscape-ecological methodology involved the topological overlay of thematic layers of landscape criteria (landcover/land use, geomorphology, flooding regime and elevation), and the subsequent analyses of their resultant combinations (Zonneveld, 1989; Zonneveld, 1995). A land use/land cover map was produced by delineating areas of relative homogeneity on ETM+ images from the different acquisition dates. Spatial landcover patterns were delineated by visual interpretation of false colour digital ETM+ scenes using criteria such as colour, shape, texture and context, dividing the entire area into map units. These units were labeled with the help of the land use map of 2005 and information gathered from field data. For the map and legend construction, different layers were overlaid to determine the proportion of land in each category. Finally a 
classification map consisting of a hierarchical legend and incorporating the characteristics of geomorphology, flooding (inundation depths), landcover and land use was produced.

\subsection{Validation}

The hyper-temporal NDVI and landscape-ecological maps were validated with the help of reported crop statistics for two and three cropping rice land use systems per district. Finally, available crop areas statistics were averaged over a five year period (2002-2007) to be used in the analysis. Regression analyses were carried out to ascertain the relationship between maps estimating land use areas estimated from maps, and those reported in district crop statistics. This was done separately for both two and three crop rice land use systems.

\section{RESULTS}

\subsection{The hyper-temporal NDVI analysis approach}

Analysis of the divergence statistics revealed a notably high average separability at the level of a 77 cluster generalization of the hyper-temporal NDVI image dataset. This coincided with a locally high peak in minimum divergence (Figure 2). A 77 cluster output was thereby determined as being the optimal clustering option for the dataset. Clusters were further characterised by incorporating elements of the collected field data, and an analysis of their temporal variability. Following cluster characterisation, and the compilation of a legend, a "77 class" NDVI unit map was produced, which was further analyzed with the incorporation of field data to determine the temporal variability of selected classes.

Various land use classes were distinguishable on the basis of crop calendar information collected from field work and NDVI profiles. Profiles showing high NDVI fluctuations peaking twice in a calendar year reflect two rice crops, whilst class profiles showing NDVI peaks three times in a calendar year represent three rice crops (Figure 3). Subsequent cluster characterisation and legend construction ultimately produced the Rice NDVI unit map shown in Figure 4.

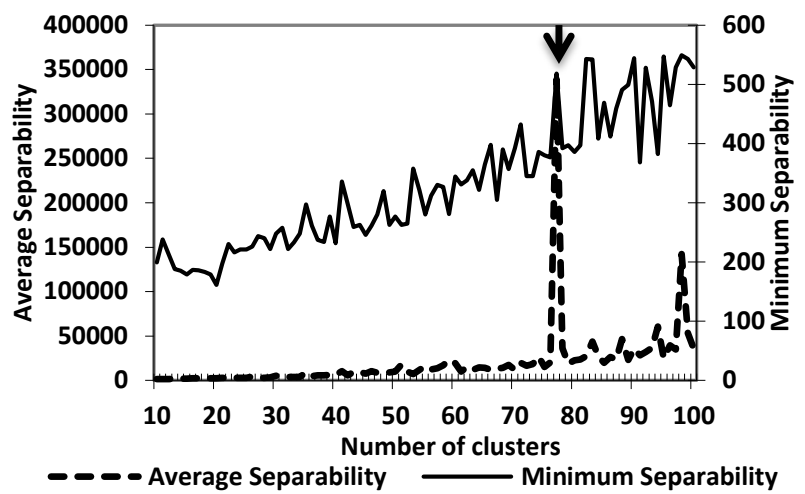

Figure 2. Divergence statistics (Avg. and Min.) used to identify the optimum number of clusters to generalise the hypertemporal NDVI image dataset.

The final legend was constructed using crop calendar data for NDVI classes, flooding regimes, location and the class temporal profiles (October 2004 to December 2007).

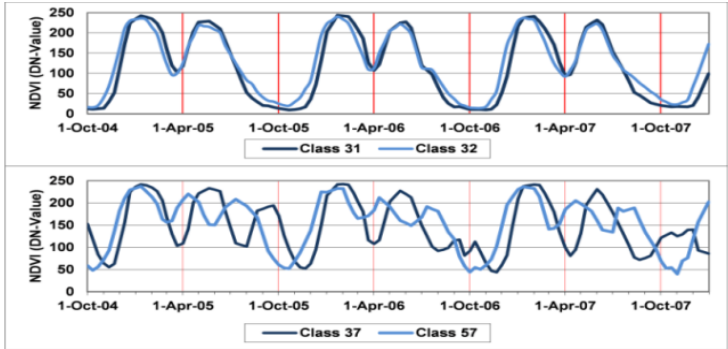

Figure 3. NDVI curves of two selected cases of two and three rice land use systems in Mekong delta, Vietnam.

The grouping of classes is based on similarities in their spatial, temporal and flooding regime information. Out of 26 rice NDVI classes, 10 groups of land use with three rice crops were obtained, along with two rice crops and two rice crops plus one upland crop under different flooding regimes. Flooding was defined as being controlled, uncontrolled, partial and extensive based on the intensity, timings and extent of flooding (Figure 4 and Figure 5).

\subsection{Landscape-ecological approach}

The landscape-ecological map consisted of homogenous land units representing terrain, geomorphology, inundation depths, land cover/land use information (based on ETM+ and Land use map 2005), and analyses of their resultant combinations. The Landscape-ecological approach has hierarchy from general to specific i.e. from terrain to geomorphology, through to flooding and to land use systems. It was only possible to distinguish land use into two rice and three crop rice systems with the help of field data and land use map, 2005 (Figure 6 and Figure 7).

\subsection{Validation}

The NDVI rice unit map exhibited a strong correlation coefficient of 0.92 for two rice crops and 0.88 for three rice crop areas reported in crop statistics data. Scatter plot analysis revealed that the regression line is close to the 1-1 line, showing that NDVI rice unit map generalised to a high degree the land use classes reported in crop statistics data. The explained variability $\left(\mathrm{R}^{2}\right)$ is found to be $74 \%$ and $76 \%$ in two rice crops and three rice crops land use systems respectively (Figure 8).

Validation of the Landscape-ecological map showed that land use class areas estimated by the map are significantly correlated with reported crop statistics, having correlation coefficients of 0.65 and 0.62 for two and three rice crops respectively. Scatter plot analysis revealed that the fitted line is not very close to 1-1 line but still it yields some generalization of reported crop statistics. Furthermore, the explained variability is $64 \%$ in two rice and $63 \%$ in three rice crop land use systems (Figure 9).

\section{DISCUSSION}

\subsection{The hyper-temporal NDVI analysis approach}

The hyper-temporal NDVI analysis approach was found to be a useful exercise to improve agricultural land use mapping. The NDVI dataset analysis approach successfully delineated the spatial distributions of all crop calendars prevailing in the Del- 
ta. Furthermore, it successfully aided in the exploration and understanding of regional flood regimes, clarifying their relationship with local rice land use systems. The derived information not only has categorical classes; but also includes temporal dimensions (mean NDVI profiles) that show how the NDVI classes behave phenologically.

For validation of the NDVI map, due to time constraints, it was not possible to collect an independent spatial dataset. Therefore, the NDVI map was validated by correlating it with reported crop statistics. These statistics were successfully generalized to a large extent by the rice NDVI unit map, which shared about $74 \%$ of its variability with reported crop statistics in two rice crop land use systems, and about $76 \%$ in three rice crop systems. The NDVI approach provided accurate (high $\mathrm{R}^{2}$ ) and effective spatial information with less user intervention due to the predominantly data-driven approach employed by the clustering algorithm. This broadly corresponds with other studies (e.g. (Sakamoto et al., 2006; Xiao et al., 2006), where it has been found that the use of NDVI time series increases a study's ability to attain more accurate mapping of agricultural land use.

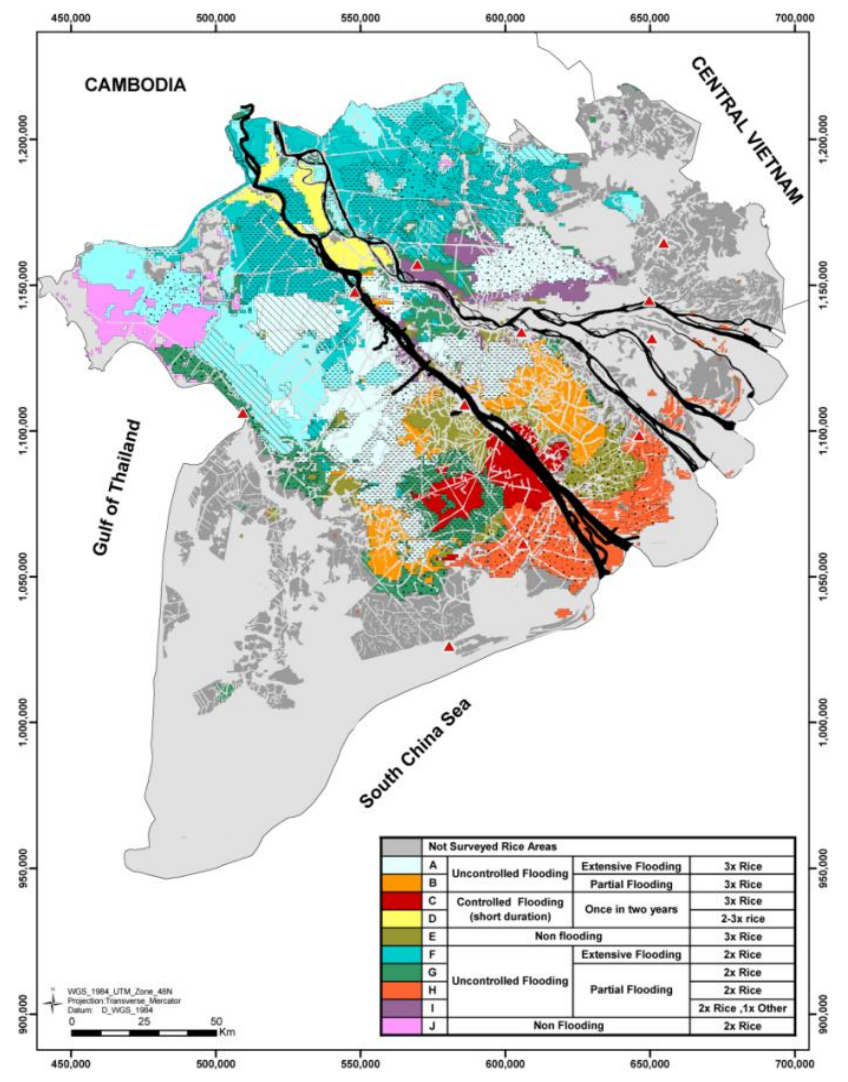

Figure 4. The NDVI rice unit map.

\begin{tabular}{|c|c|c|c|c|c|c|c|c|c|c|c|c|c|c|c|c|c|}
\hline 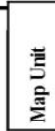 & \multicolumn{2}{|l|}{ 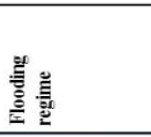 } & 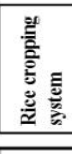 & 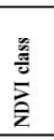 & 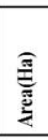 & 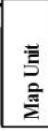 & \multicolumn{2}{|c|}{ 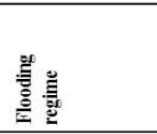 } & 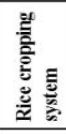 & 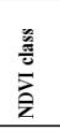 & 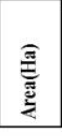 & $\begin{array}{l}\text { 혀 } \\
\text { : } \\
\text { : }\end{array}$ & \multicolumn{2}{|l|}{ 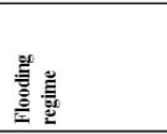 } & 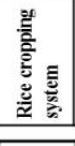 & 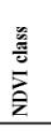 & 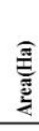 \\
\hline \multirow{5}{*}{$<$} & \multirow{6}{*}{ 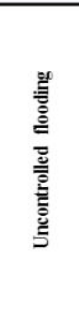 } & \multirow{6}{*}{ 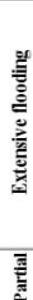 } & \multirow{7}{*}{ 芯 } & 8 & 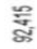 & \multirow{10}{*}{ L } & \multirow{10}{*}{ 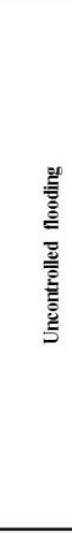 } & \multirow{10}{*}{ 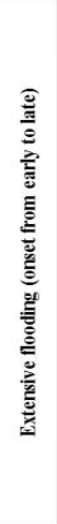 } & \multirow{10}{*}{$\frac{\stackrel{\tilde{J}}{\pi}}{\pi}$} & శ্ল & 袢 & & \multirow{9}{*}{ 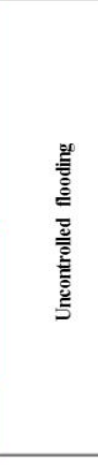 } & \multirow{9}{*}{ 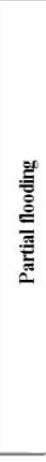 } & \multirow{7}{*}{ 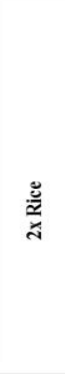 } & $\otimes$ & 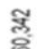 \\
\hline & & & & $\because$ & 范 & & & & & & :్ఞ & 10 & & & & $\therefore$ & g \\
\hline & & & & $E$ & : & & & & & 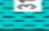 & 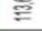 & & & & & & \\
\hline & & & & $\cdots$ & & & & & & 81 & ; & & & & & 8 & 范 \\
\hline & & & & & & & & & & 9 & 焉 & & & & & $\infty$ & $\overline{0}$ \\
\hline$\infty$ & & & & $E$ & 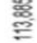 & & & & & $=$ & 桑 & $x$ & & & & 字 & $\approx$ \\
\hline 0 & \multirow{2}{*}{\multicolumn{2}{|c|}{ 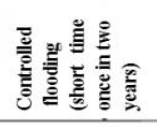 }} & & 8 & జ & & & & & $\because 8$ & 苝 & & & & & ए. & 器 \\
\hline 0 & & & $3: 3$ & 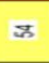 & : & & & & & 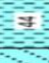 & : & - & & & 苞 & 6 & 응 \\
\hline \multirow[b]{2}{*}{ | | } & \multirow{2}{*}{\multicolumn{2}{|c|}{ 突 }} & & ణ & 产 & & & & & $\alpha$ & 홍 & & & & & & \\
\hline & & & 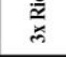 & 8 & 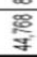 & & & & & 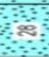 & 爱 & $\rightarrow$ & \multicolumn{2}{|c|}{ Non flooding } & $\approx \stackrel{\check{\check{\Xi}}}{\simeq}$ & F & 离 \\
\hline
\end{tabular}

Figure 5. The detailed legend of the NDVI rice unit map. 


\section{4, Part XXX}

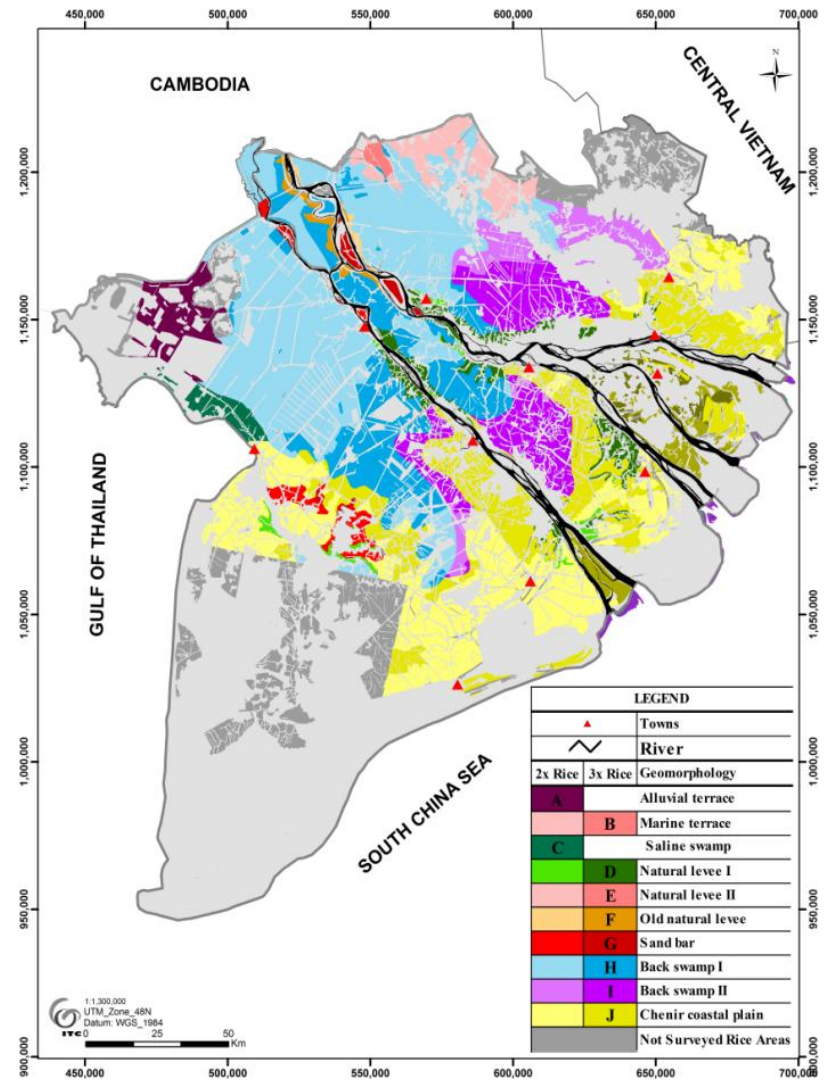

Figure 6. The Landscape-ecological map.

\subsection{The Landscape-ecological approach}

The landscape-ecological approach used in this study is less sensitive to the temporal aspects of landcover and land use, and is therefore less suitable for mapping complex agricultural land use systems. The approach uses limited multi-temporal imagery, which can misclassify or omit the finer details of land use systems of high cropping intensity and more complex crop calendars (Cihlar, 1996; Zhang et al., 2009). The use of subjective photo-interpretation by the user can potentially add to the errors, given the improbability of the user delineating exactly the same categories repeatedly. The approach is also hindered by issues surrounding the sourcing of cloud-free imagery. Furthermore, the use of supplementary datasets potentially adds to the need for more resources geared towards data purchasing and processing. It is also notable that the output of the Landscape-ecological approach only presents spatial information within a single timeframe. As such, it does not incorporate aspects concerning the historical time-series behavior of land use systems, useful for studying special practices like silt deposition in field on 2-3 years cycles, or crop rotation practices.

The validation analysis showed that the Landscape-ecological map explained $64 \%$ and $63 \%$ of the variability in reported crop statistics for two rice crop and three rice crop land use systems respectively. Less agreement with the crop statistics is apparent in comparison to the NDVI rice unit map, with the regression line lying "not very close" to the 1-1 line. The low correlation can be attributed to the techniques limitations in delineating complex land use systems by employing imagery acquired at intermittent times, and with a limited temporal resolution and extent. Such a limitation in terms of its impact on increasing the potential for errors in interpretation and processing has also been highlighted by Homer et al., (1997). Similarly Zhang et al., (2009) and Loveland et al., (2000) found that land cover phenology is an important indicator to accurately characterise land cover, and one which is not possible to follow using imagery acquired at irregular temporal resolutions such as those used in the landscape-ecological approach.

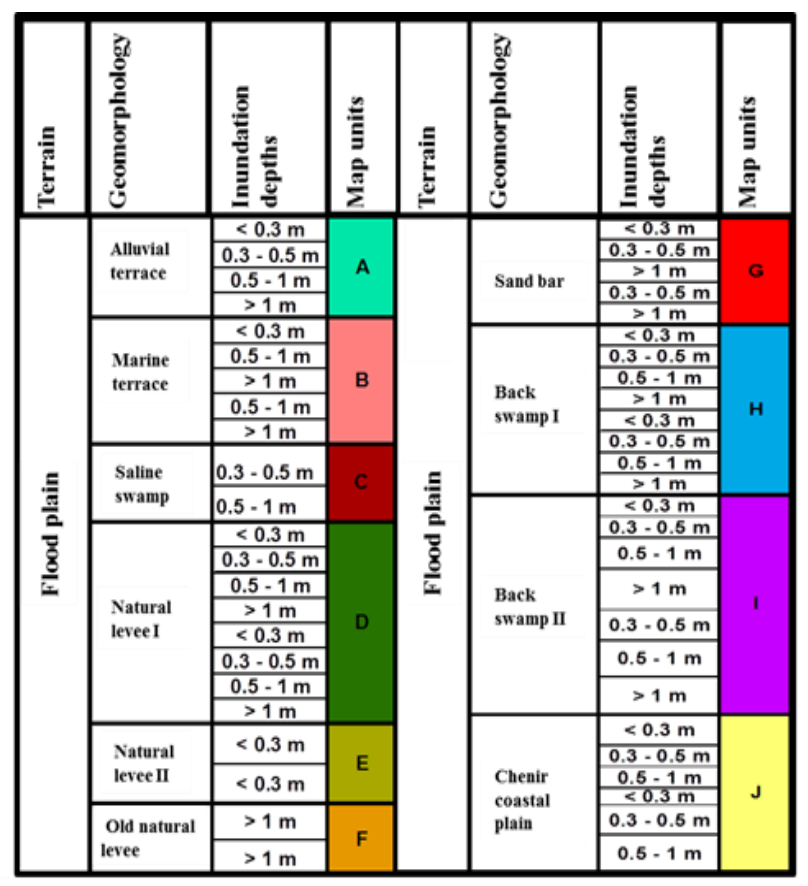

Figure 7. The detailed legend of the Landscape-ecological map.

\section{CONCLUSION}

On the basis of the outlined results, this study concludes that the hyper-temporal NDVI analysis approach is highly effective in classifying land use in heterogeneous and highly intensive crop areas like the Mekong Delta, Vietnam. The approach successfully adapted to and incorporated the phenomena of annual flooding, and its interaction with regional agricultural land use systems. Furthermore, the approach was found to be relatively easy to implement, more cost effective, and involved less subjective user intervention in the analysis process. The Landscape-ecological approach did succeed in identifying landscape units and land use systems, however this was of a more limited scope. In terms of efficiency, the approach was more time consuming, with a higher associated cost, and was shown to be more prone to errors due to digitization errors, or misinterpretations. Overall, the hyper-temporal NDVI analysis approach produced an output that was more accurate, explaining $10 \%$ more of the variability in the reported crop statistics than the Landscape-ecological map. 

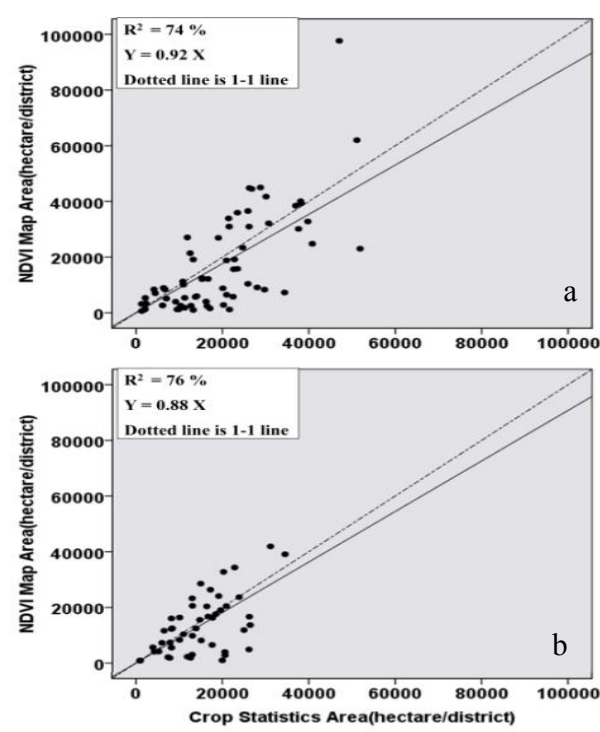

Figure 8. Scatter plots showing, two rice crop (a) and three rice crop (b) land use systems of the NDVI rice unit map versus crop statistics.
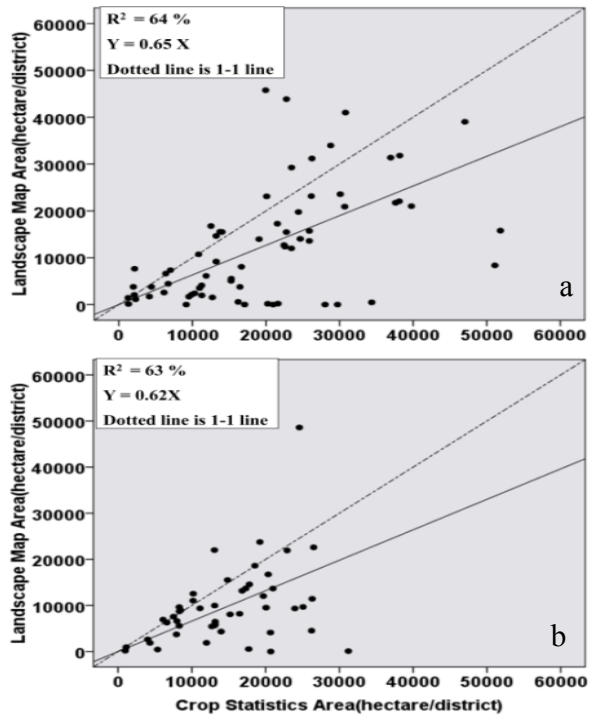

Figure 9. Scatter plots showing two rice crop (a) and three rice crop (b) areas of the Landscape-ecological map versus crop statistics.

\section{REFERENCES}

Cihlar, J., 1996. Identification of contaminated pixels in AVHRR composite images for studies of land biosphere. Remote Sensing of Environment, 56(3), pp. 149-163.

de Bie, C. A. J. M., Khan, M. R., Toxopeus, A. G., Venus, V. and Skidmore, A. K., 2008. Hyper temporal image analysis for crop mapping and change detection. In:
ISPRS : Proceedings of the XXI congress: Comm. VII, WG VII/5, Beijing, pp. 803-812.

Haruyama, S. and Shida, K., 2008. Geomorphologic land classification map of the Mekong Delta utilizing JERS-1 SAR images. Hydrological Processes, 22(9), pp. 1373-1381.

Homer, C. G., Ramsey, R. D., Edwards, T. C. and Falconer, A., 1997. Landscape cover-type modeling using a multiscene thematic mapper mosaic. Photogrammetric Engineering and Remote Sensing, 63(1), pp. 59-67.

Khan, M. R., de Bie, C. A. J. M., van Keulen, H., Smaling, E. M. A. and Real, R., 2010. Disaggregating and mapping crop statistics using hypertemporal remote sensing. International Journal of Applied Earth Observation and Geoinformation, 12(1), pp. 36-46.

Loveland, T. R., Reed, B. C., Brown, J. F., Ohlen, D. O., Zhu, Z., Yang, L. and Merchant, J. W., 2000. Development of a global land cover characteristics database and IGBP DISCover from $1 \mathrm{~km}$ AVHRR data. International Journal of Remote Sensing, 21(6/7), pp. 1303-1330.

McCloy, K. R., 2006. Resource Management Information Systems: Remote Sensing, GIS and Modeling. CRC Press, Boca Raton, Florida, pp. 575.

Minh, V. Q., 1995. Use of Soil and Agro hydrological Characteristics in Developing Technology Extrapolation Methodology: A Case Study of the Mekong Delta, Vietnam, University of the Philippines.

Sakamoto, T., Van Nguyen, N., Ohno, H., Ishitsuka, N. and Yokozawa, M., 2006. Spatio-temporal distribution of rice phenology and cropping systems in the Mekong Delta with special reference to the seasonal water flow of the Mekong and Bassac rivers. Remote Sensing of Environment, 100(1), pp. 1-16.

Swain, P. H. and Davis, S. M., 1978. Remote sensing : the quantitative approach. McGraw-Hill, New York, pp. 396.

Turner, M. G., 1989. Landscape Ecology: The Effect of Pattern on Process. Annual Review of Ecology and Systematics, 20, pp. 171-197.

Xiao, X., Boles, S., Frolking, S., Li, C., Babu, J. Y., Salas, W. and Moore III, B., 2006. Mapping paddy rice agriculture in South and Southeast Asia using multitemporal MODIS images. Remote Sensing of Environment, 100(1), pp. 95-113.

Yamashita, A., 2005. Zoning for risk assessment of waterrelated natural disasters in the Mekong Delta. Can Tho, Can Tho University, Vietnam.

Zhang, X., Friedl, M. A. and Schaaf, C. B., 2009. Sensitivity of vegetation phenology detection to the temporal resolution of satellite data. International Journal of Remote Sensing, 30(8), pp. 2061-2074.

Zonneveld, I. S., 1989. The land unit - A fundamental concept in landscape ecology, and its applications. Landscape Ecology, 3(2), pp. 67-86.

Zonneveld, I. S., 1995. Land ecology: an introduction to landscape ecology as a base for land evaluation, land management and conservation. SPB Academic Publishing, Madison, pp. 199. 